\title{
Fracture of high performance materials under multiaxial compression and thermal effect
}

\author{
Igor Lubimovich Shubin ${ }^{a^{*}}$, Yuri Vladimirovich Zaitsev ${ }^{b}$, Vladimir Ivanovich Rimshin ${ }^{c}$, \\ Vladimir Leonidovich Kurbatov ${ }^{d}$ and Pyatimat Sulambekovna Sultygova ${ }^{\mathrm{e}}$
}

${ }^{a}$ Research institute of construction physics RAASN, Russia, 127237 Moscow, Lokomotivnaya St., 21, Russia

${ }^{b}$ Russian Academy of Architecture and Building Sciences; Vienna University of Technology Russia, 107031, Moscow, Dmitrovka St., 24, Russia

"FGBOU VO "National Research Moscow State Construction University" (NIU MGSU), Russia; 129337, Moscow, Yaroslavl Highway, 26, Russia

${ }^{d B e l g o r o d ~ s t a t e ~ t e c h n o l o g i c a l ~ u n i v e r s i t y ~ o f ~ V . ~ G . ~ S h u k h o v, ~ R u s s i a, ~ 308012, ~ B e l g o r o d, ~ K o s t y u k o v ~ S t ., ~ 46, ~ R u s s i a ~}$

eIngush State University, 386132 Nazran, Gamurzievo municipality, Trunk St., 39, Russia

\begin{tabular}{l}
\hline A R T I C L EI N F O \\
\hline Article history: \\
Received 6 October, 2016 \\
Accepted 3 February 2017 \\
Available online \\
6 February 2017 \\
\hline Keywords: \\
Strength \\
Multiaxial compression \\
Compressive and tensile stresses \\
Temperature effect \\
Temperature influence
\end{tabular}

\section{Introduction}

There is no consensus on the strength of concrete and other brittle materials under multiaxial compression among researchers (Calvet 1969; Kupfer et al. 1969; Leadbetter 1965; Raju 1971; Schickert \& Winkler 1977; Stroeven 1973 Huang et al. 2015; Nitka \& Tejchman 2015; Linse \& Kupfer 2013; Lim et al. 2016; Van Mier \& Van Vliet 2002; Tschegg et al. 2015). Thus, in some studies, the

\begin{abstract}
The article discusses the strength of concrete and other brittle materials in the case of nonuniform biaxial type of compression $\left(\sigma_{1}>\sigma_{2}>0\right)$ and triaxial compression of $\sigma_{1}>\sigma_{2}=\sigma_{3}>0$ type (it was assumed that $\sigma>0$ corresponds to compression). It is noted that, when considering the biaxial loading in the accepted model, probabilistic nature of distribution of stresses along the contour of pores and inclusions, i.e. stress causing formation and propagation of cracks in the material, plays an important role. Moreover, the stress across the circuit pores was regarded as a three-dimensional random field of $S(\alpha, b, \gamma, \omega)$, where $\omega$ - is a random argument. Considering the average number of overshoots $N_{R}$ we believed that the random field of $S$ is not homogeneous (not stationary): its expectation is not constant, but is a function of nonrandom arguments $M_{s}$ $=M_{s}(\alpha ; 6 ; \gamma)$. External load, corresponding to $N_{R}=$ const (and at the same time constant of level exceedance probability), first increases and then decreases a little. Heating up to $300^{\circ} \mathrm{C}(573 \mathrm{~K})$ and $400^{\circ} \mathrm{C}(673 \mathrm{~K})$ leads to violations, and long-term load leads to significant changes in the macro- and microstructure of concrete.
\end{abstract}

(C) 2017 Growing Science Ltd. All rights reserved.

\footnotetext{
* Corresponding author.

E-mail addresses: i.shu.asu@bk.ru (I. L. Shubin) 
strength of materials under multiaxial compression did not differ from the strength under uniaxial compression. In other studies the increase in strength was obtained under biaxial compression. There is disagreement about this increase: the maximum increase in strength varies in different studies from 1.3 to 2.7 . The cracking boundary in concrete under biaxial compression was studied much less than the strength.

The fact that the relative level of cracks formation is a material constant and does not depend on the ratio of principal stresses was confirmed by many investigators. The ways of the development of the adopted approach in relation to the case of multiaxial compression will be specified next. The general case of non-uniform biaxial $\left(\sigma_{1}>\sigma_{2}>0\right)$ compression and triaxial compression of $\sigma_{1}>\sigma_{2}=\sigma_{3}>0$ type (we assume that $\sigma>0$ corresponds to compression) will also be examined.It should be noted that when considering the biaxial loading in the accepted model, probabilistic nature of distribution of stresses along the contour of pores and inclusions, i.e. stress resulting in formation and propagation of cracks in the material, plays an important role. With that knowledge in mind, the modified calculation model for the case of biaxial compression is based on the consideration of volumetric stressed state of three-dimensional body and on the analysis of random shape of pores and grains of aggregate.

First, it should be considered the formation of cracks in the concrete at the microstructure level, i.e. near the material pores (Zaitsev et al. 2016). Real material pores, as mentioned above, may have very different random shape, which leads to the random nature of pores contour stress. Regardless of pores shape the nature of the stresses concentration is subject to the same laws both in plane elastic and spatial problems. Therefore, when describing stresses on the three-dimensional contour of pores it is possible to use a statistical simulation results obtained for a plane problem.

\section{Method and results}

For a plane problem case of the axial load let's define the probability that a random function of $S$ exceeds a certain level, i.e. that tensile stresses on pore contour reach a critical value corresponding to the beginning of cracks, existing on pore contour. Stresses of $S$, acting on the contour of the space of the random shape, will be considered as a random function. Its nonrandom arguments will be two spherical coordinates of $\alpha$ and $\beta$, as shown in Fig. 1. The position of the considered point on the contour of the plane and the angle of $\gamma$ characterize the orientation relative to the external forces of the site, which is subject to stress. Thus, the stress on pore contour are regarded as a random three-dimensional field of $S(\alpha, \beta, \gamma, \omega)$, where $\omega$ is the random argument. To use the value of $\gamma$, which characterizes the orientation of the site under consideration as a nonrandom argument, it is necessary to construct a continuous vector field on the surface of the spherical space.

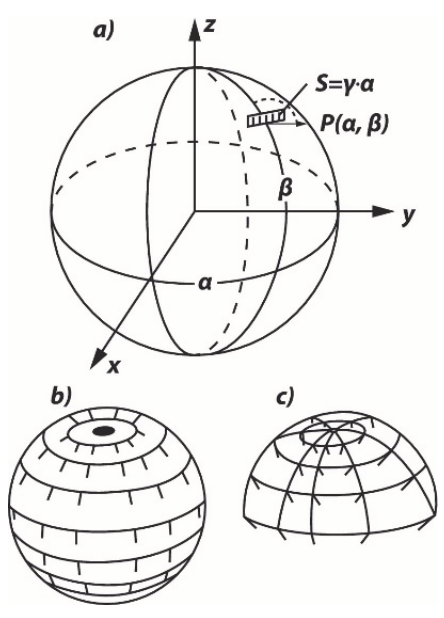

Fig. 1. Analysis of stresses along the contour of the spatial pore of random form as a random function of three arguments: (a ) the emergence of singular points on the vector field constructed on the surface of the sphere; (b) continuous vector field on the surface of a hemisphere of в. 
The theory of constraints, one of the branches of the topology, shows that continuous vector field cannot be constructed on the surface of the sphere. This is connected with the appearance of singular points "obstructions" (Fig.1b) on the poles of the sphere. They prevent the spreading of a continuous field on the entire surface. It can be shown that some implicit techniques allow to avoid this difficulty. In this case, the symmetry of problems under consideration allows to review stress only of about onehalf of an air space. It will be possible to construct a continuous vector field on the hemisphere surface (Fig. 1b), if you introduce $\gamma$, as shown in Fig. 1. Reviewing the average number of overshoots of $N_{R}$, we consider that the random field of $S$ is not homogeneous (stationary): its expectation is not constant, but is a function of non-random arguments $M_{s}=M_{s}(\alpha ; \beta ; \gamma)$. Therefore graphic of $M_{s}=(\alpha, \beta, \gamma)$ is some surface in four-dimensional space. Fig. 2 shows the three-dimensional sections of the surface at some fixed values of $\beta$ and different values of $\sigma$.
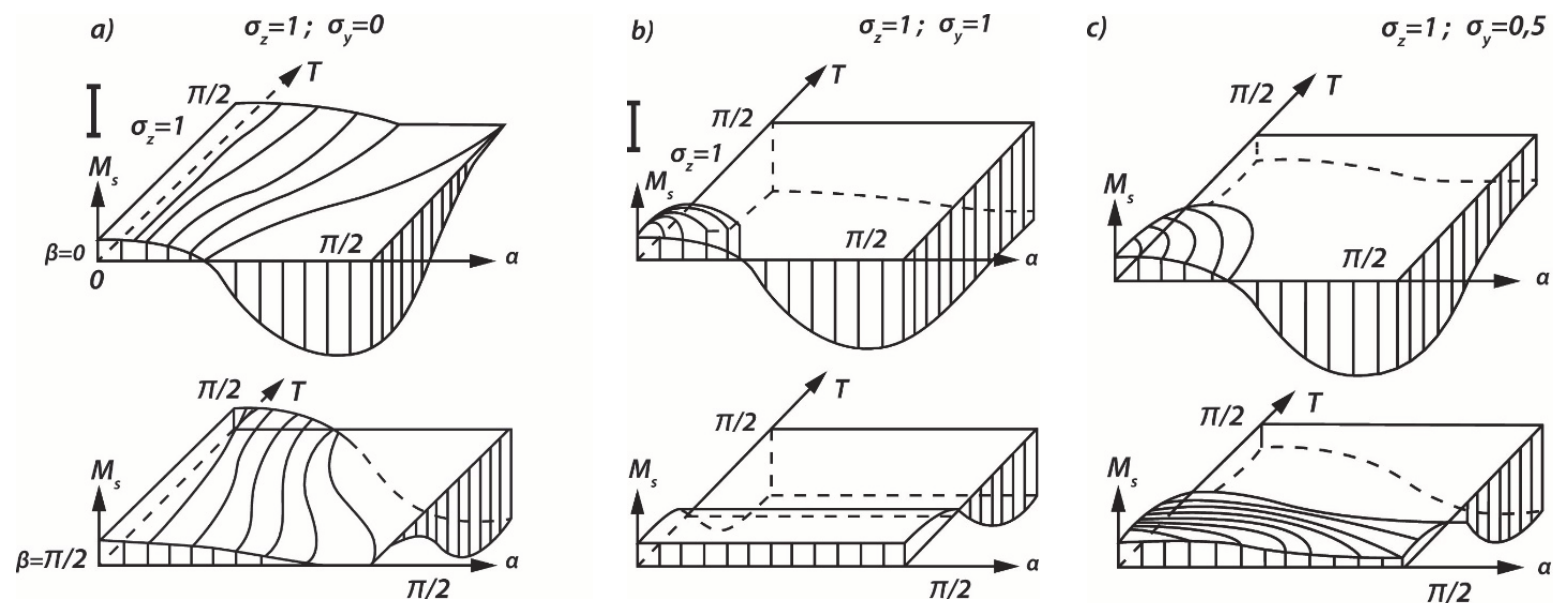

Fig. 2. The expectation of stress along the contour of the pores of random shapes a - under axial compression; $b$ - with a uniform biaxial compression; в - at non-uniform biaxial compression

In the mathematical sense, all of the tasks on the issues of random fields are very complex. Thus, for a two-dimensional homogeneous (stationary) isotropic field solutions were obtained quite recently. There are no solutions for more complex cases of three-dimensional inhomogeneous field yet. In this regard, the definition of average number of overshoots of our random field will be performed approximately. The average number of overshoots of a random field in its individual sections with $\alpha=$ const and $\beta=$ const will be defined and then the results will be summarized. Fig. 3 illustrates the results of these calculations, where the abscissa is the ratio of principal stresses $\sigma_{1}: \sigma_{2}$, and the vertical axis is the average number of overshoots $\left(N_{R}\right)$ over some constant level of $R *$. Individual lines correspond to different values of external stress $\sigma_{y}$ and $\sigma_{z}$ : the greater the stresses are, the higher the $N_{R}$ is and the higher the curve lies.

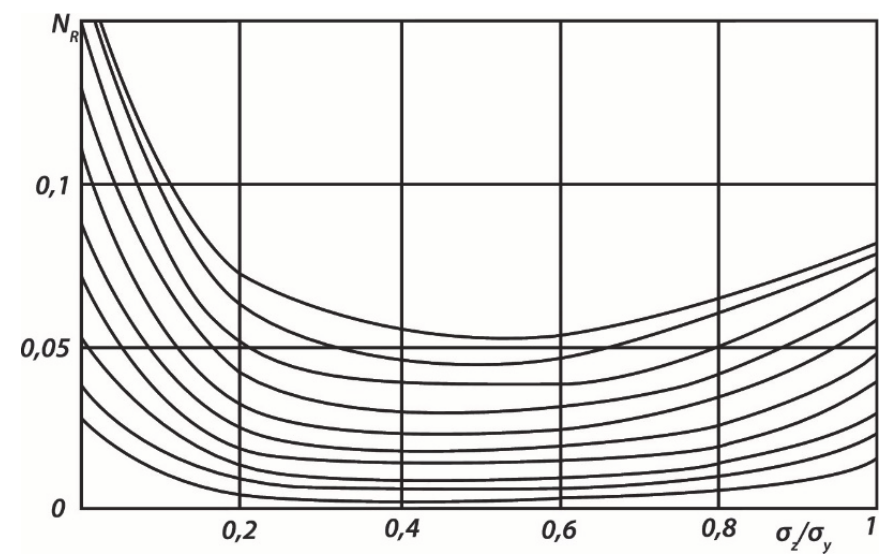

Fig. 3. Average number of overshoots for a constant level of stress as a function of the ratio of principal stresses. 
Fig. 3 shows that when there is an increase in the ratio of $\sigma_{y}: \sigma_{z}$ the value of $N_{R}$ first sharply decreases and then slightly increases. This phenomenon can also be explained by purely eureka way: when $\sigma_{y}: \sigma_{z}=0$, i.e. under uniaxial compression (Fig. 2a), the site of a random field, where tensile stresses act, is quite large (the upper part of the field is marked by horizontals), with the maximum ordinate of $M_{s}^{\text {mah }}=0,5$ retaining its value for all $\gamma$.

For uniform biaxial compression of $\sigma_{y}: \sigma_{z}=1$ (Fig. 2b) a relevant section becomes smaller, which reduces the average number of overshoots, although the maximum ordinate of $\left(M_{s}^{\text {mah }}=0,5\right)$ retains its value for all of $\alpha$, if $\gamma=0$ and $\beta=\pi / 2$. Finally, if $\sigma_{y}: \sigma_{z}=0,5$ (biaxial uneven compression Fig.2в), the maximum ordinate of $\left(M_{s}^{m a h}=0,5\right)$ occurs only at one point of $(\alpha=\gamma=0)$; i.e. the average number of overshoots should be even less. All these findings are in line with the results shown in Fig. 3 . Compared with the curves under consideration, external load corresponding to $N_{R}=$ const (and with it the constant probability of level exceedance) must follow inverse relationship - it first increases and then decreases a little. Fig. 4 illustrates this pattern. Here every dashed curve gives the relationship between the principal stresses of $\sigma_{y}$ and $\sigma_{z}$, corresponds to a constant probability of exceedance of $R^{*}$ level. Noteworthy is the fact that, despite the significant changes of level exceedance probability (digits on the curves) the positions of the curves change very little. Moreover, if proceed not from the $95 \%$, which roughly corresponds to the upper curve, but from the other value of probability for the crack border $R_{T}^{o}$, the law of $R_{T}^{o}$ variations will not change significantly at $\sigma_{y}: \sigma_{z}$ changing. These results refer to the case where failure of the material begins at the level of the microstructure.

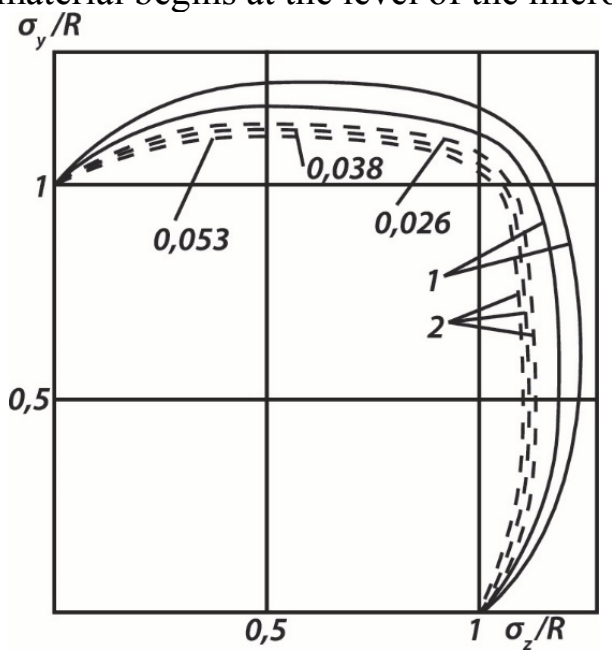

Fig. 4. The relationship between the principal stresses corresponding to a constant probability of exceeding a given level of $R *$ stresses along the contour of the pores

1 - at the level of the macrostructure $\left(\right.$ at $\left.300^{\circ} \mathrm{C}\right)$;

2 - at the level of the microstructure $\left(\right.$ at $\left.400^{\circ} \mathrm{C}\right)$

The same approach is also possible for the material under temperature action to $300{ }^{\circ} \mathrm{C}(573 \mathrm{~K})$ and $400^{\circ} \mathrm{C}(673 \mathrm{~K})$ (Zaitsev \& Sultygova 2016). Fig. 5 shows macro- and microstructure of concrete samples $(10 \times 10 \times 40 \mathrm{~cm})$, heated under the load of $\eta^{\prime}=0,5$ to $t=300^{\circ} C$ and $t=400^{\circ} C$. There is a weakened structure and the presence of defective contacts with both large and small aggregates. Mortar separations from granite, 10 - 100 microns gaps and 20 - 100 microns pores catenating along the contact can be seen under the microscope.

The total macroporosity in these samples is $6 \%$. The pores of irregular shape with cut contours are dominated. Substantial number of microcracks with opening width of 5-30 microns, developing both in pores and in mortar part of the sample, is visible. We observe that the structure of both large and fine aggregate is weakened by the presence of defects such as cracks and segregations. 


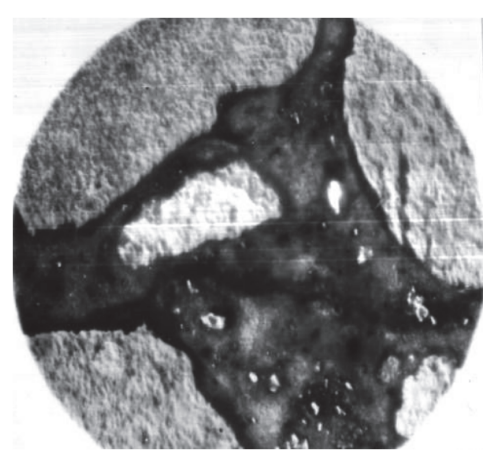

(a)

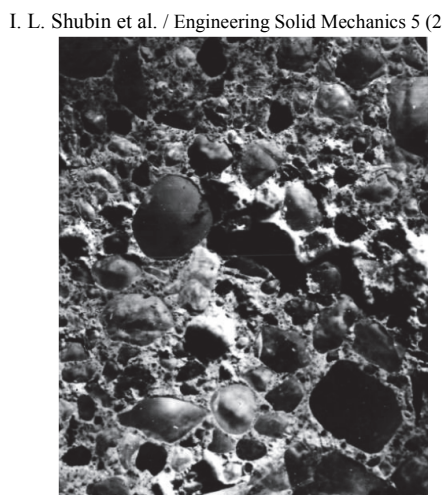

(b)

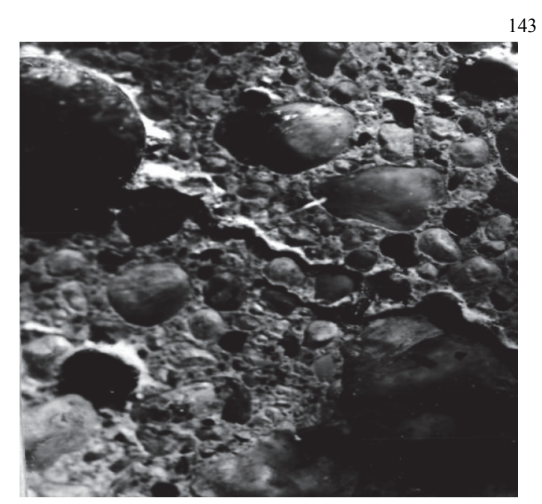

(c)

Fig. 5. Micro- and macrostructure of concrete heated to $300^{\circ} \mathrm{C}$ and $400^{\circ} \mathrm{C}$ at $\eta^{\prime}=0,5 ; \eta=0$ :

$$
a-t=300^{\circ} C ; b-t=400^{\circ} C ; c-t=300^{\circ} C
$$

Fig. 6 shows a concrete structure subjected to short-term temperature exposure up to $t=300^{\circ} C$ before long-term test under load of 0.7 from the destructive rate. The overall structure of this sample has a lower density and higher porosity. Large number of deep cavernous spaces and intensive development of cracks in the mortar of the sample can be seen under macrographic examination even at low magnification.

Joints between binding material and aggregates, both large and fine, are weakened due to the development of pores chains along them, the presence of segregations and $10-200$ microns gaps. A similarity of structure segregation was seen in this sample. Thus, heating up to $t=300^{\circ} C(573 K)$ and $t=400^{\circ} C(673 \mathrm{~K})$ leads to violations, and the results of long-term load are significant changes in the macro- and microstructure of concrete.

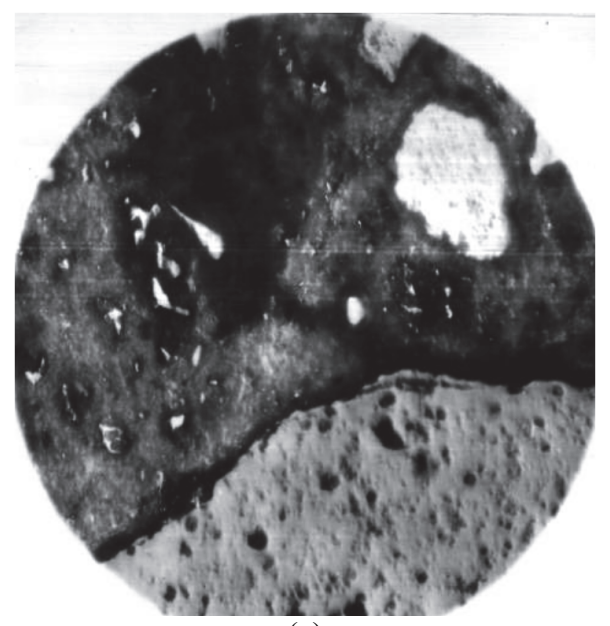

(a)

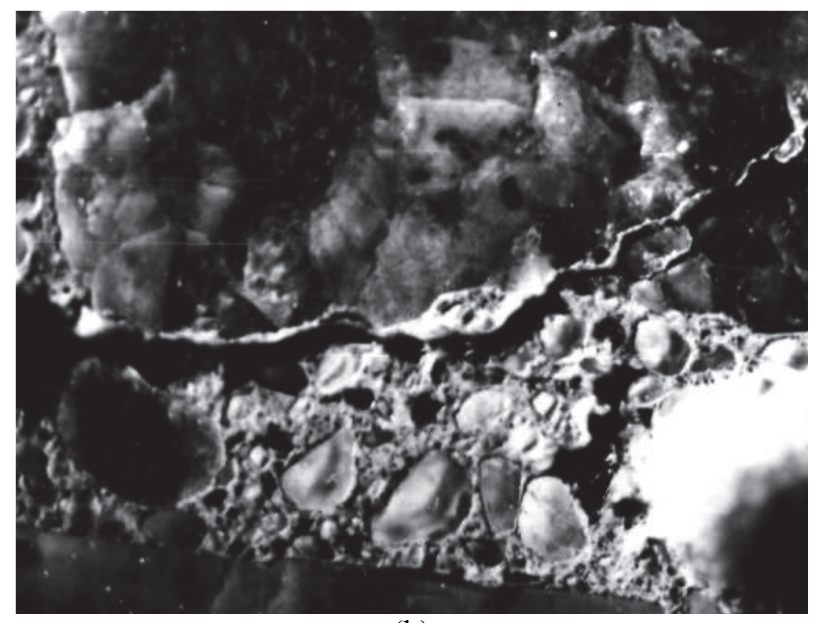

(b)

Fig. 6. Micro- and macrostructure of concrete subjected to prolonged downloaded when $\eta=0,7$, after a brief heating to $300^{\circ} \mathrm{C}$ at $\eta^{\prime}=0: \mathrm{a}$ - macrostructure; $\mathrm{b}$ - microstructure

\section{Conclusions}

1. Under uniform biaxial compression $\sigma_{y}: \sigma_{z}=1$ a relevant section becomes smaller, which reduces the average number of overshoots, although the maximum ordinate $\left(M_{s}^{m a h}=0,5\right)$ retains its value for all of $\alpha$.

2. If $\gamma=0$ and $\beta=\pi / 2$ at $\sigma_{y}: \sigma_{z}=0,5$ (biaxial uneven compression), the maximum ordinate $\left(M_{s}^{\text {mah }}=0,5\right)$ occurs only at one point $(\alpha=\gamma=0)$; i.e. the average number of overshoots should be even less. All these findings are in line with the results shown. 
3. Compared with the curves under consideration, external load corresponding to $N_{R}=$ const (and with it the constant probability of level exceedance) must follow inverse relationship - it first increases and then decreases a little.

4. These results refer to the case where failure of the material begins at the level of the microstructure.

The same approach is also possible for the material to be exposed to the temperature of $300^{\circ} \mathrm{C}$ $(573 \mathrm{~K})$ and $400^{\circ} \mathrm{C}(673 \mathrm{~K})$.

5. The heating up to $t=300^{\circ} C(573 K)$ and $t=400^{\circ} C(673 K)$ leads to violations, and the results of long-term load are significant changes in the macro- and microstructure of concrete.

\section{References}

Calvet, H. (1969). Etude sur modèle plan des déformations sous charge autour d'un granulat. In Colloque geotechnique, Toulouse.

Huang, Y. J., Yang, Z. J., Ren, W. Y., Liu, G. H., \& Zhang, C. Z. (2015). 3D in-situ XCT image based meso-scale fracture modelling and validation of concrete using voxel hexahedron meshing and damage plasticity model. International Journal of Solids Structure, 67, 340-352.

Kupfer, H., Hilsdorf, H. K., \& Rusch, H. (1969, August). Behavior of concrete under biaxial stresses. In Journal Proceedings (Vol. 66, No. 8, pp. 656-666).

Nitka, M., \& Tejchman, J. (2015). Modelling of concrete behaviour in uniaxial compression and tension with DEM. Granular Matter, 17(1), 145-164.

Leadbetter, M. R. (1965). On crossings of arbitrary curves by certain Gaussian processes. Proceedings of the American Mathematical Society, 16(1), 60-68.

Linse, D., \& Kupfer, H. (2013, April). Behaviour of Concrete under Triaxial Loading. In ICF3, Munich (Germany) 1973.

Lim, J. C., Ozbakkaloglu, T., Gholampour, A., Bennett, T., \& Sadeghi, R. (2016). Finite-Element Modeling of Actively Confined Normal-Strength and High-Strength Concrete under Uniaxial, Biaxial, and Triaxial Compression. Journal of Structural Engineering, 142(11), 04016113.

Raju, N. K. (1970). Strain distribution and microcracking in concrete prisms with a circular hole under uniaxial compression. Journal of Materials, 5(4), 901.

Van Mier, J. G. M., \& Van Vliet, M. R. A. (2002). Uniaxial tension test for the determination of fracture parameters of concrete: state of the art. Engineering Fracture Mechanics, 69(2), 235-247.

Schickert, G., \& Winkler, H. (1977). Versuchsergebnisse zur Festigkeit und Verformung von Beton bei mehraxialer Druckbeanspruchung (No. 277).

Stroeven, P. (1973). Some aspects of the micromechanics of concrete (Doctoral dissertation, TU Delft, Delft University of Technology).

Tschegg, E. K., Schneemayer, A., Merta, I., \& Rieder, K. A. (2015). Energy dissipation capacity of fibre reinforced concrete under biaxial tension-compression load. Part II: Determination of the fracture process zone with the acoustic emission technique. Cement and Concrete Composites, 62, 187-194.

Zaitsev Y., Shubin I.\& Sultygova P. (2016). Destruction of high-strength materials under multiaxial compression. In the Proceedings of the IX Academic reading RAASN - International scientific conference "The durability, strength and fracture mechanics of concrete, reinforced concrete and other construction materials", St. Petersburg, pp. 35-39.

Zaitsev Y.\& Sultygova P. (2016). Inhomogeneous structure of long-term strength and deformability of the concrete after exposure to temperatures of $400^{\circ} \mathrm{C}$ in terms of mechanics $(673 \mathrm{~K})$. In the Proceedings of the IX Academic reading RAASN - International scientific conference "The durability, strength and fracture mechanics of concrete, reinforced concrete and other construction materials", St. Petersburg, pp.26-30.

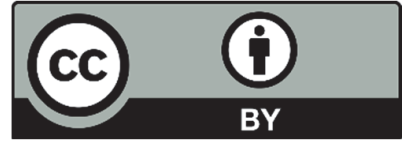

(C) 2017 by the authors; licensee Growing Science, Canada. This is an open access article distributed under the terms and conditions of the Creative Commons Attribution (CC-BY) license (http://creativecommons.org/licenses/by/4.0/). 